\title{
Internalizing Symptoms as Mediators of Lifetime Incidence of Trauma and Quality of Life among Out-of-School Youths
}

\author{
Yeon Jung Lee', So Hee Lee ${ }^{2}$, Woori Han², Moon-Soo Lee ${ }^{3}$, \\ Dae Hyun $\mathrm{Um}^{2}$, Eun Hee Chung ${ }^{4}$, and Jeong Min Eom ${ }^{5}$ \\ ${ }^{1}$ Department of Psychiatry, College of Medicine, Soonchunhyang University, Seoul Hospital, Seoul, Korea \\ ${ }^{2}$ Department of Psychiatry, National Medicine Center, Seoul, Korea \\ ${ }^{3}$ Department of Psychiatry, College of Medicine, Korea University, Guro Hospital, Seoul, Korea \\ ${ }^{4}$ Department of Pediatrics, College of Medicine, Chungnam National University, Daejeon, Korea \\ ${ }^{5}$ Department of Obstetrics and Gynecology, College of Medicine, Hanyang University, Seoul, Korea
}

\begin{abstract}
Objectives: The present study aimed to investigate the relationships among the lifetime incidence of trauma, internalizing symptoms, and quality of life (QoL) in out-of-school youths (OSYs).

Methods: We recruited 50 OSYs in South Korea. Participants completed the following surveys: completed Lifetime Incidence of Traumatic Events for children, Youth Self Report, and The KIDSCREEN-27 QoL measure for children and adolescents. Mediation analysis was conducted to test the research hypotheses.

Results: The mean lifetime incidence of traumatic events among OSYs was 3.27 (standard deviation, 2.41). Internalizing symptoms significantly mediated the lifetime incidence of trauma and QoL. OSYs with fewer internalizing symptoms exhibited a better QoL in the domain of psychological well-being, although their lifetime incidence of trauma was higher.

Conclusion: The results of current study suggest that assessment and therapeutic intervention with regard to internalizing symptoms are needed to increase the QoL of OSYs.
\end{abstract}

Key Words: School dropout; Adolescent; Anxiety; Depression; Quality of life.

Received: March 14, 2018 / Revision: April 10, 2018 / Accepted: April 14, 2018

Address for correspondence: So Hee Lee, Department of Psychiatry, National Medical Center, 245 Eulji-ro, Jung-gu, Seoul 04564, Korea Tel: +82-2-2260-7311, Fax: +82-2-2268-5028, E-mail: psyhee@hanmail.net

\section{INTRODUCTION}

As of 2013, there are approximately 400000 out-of-school youths (OSYs) in South Korea; of these, the location of approximately $280000(70 \%)$ is unknown. ${ }^{1)}$ Each year, approximately $6000-7000$ students (i.e., $1 \%$ of all students), drop out of school in South Korea. Although this school dropout rate is low when compared with other developed countries (USA: $7.4 \%$, Germany: $6.5 \%$, Japan: $1.3 \%$ ), ${ }^{2}$ great care should be taken to help these students better cope with their adverse situations, given the serious disadvantages for both OSYs, such as lost opportunities for education and difficulties with social integration, and for overall society, such as reductions in qualified human resources and increases in social welfare and crime costs. ${ }^{3)}$

OSYs face various traumatic events during the period in

This is an Open Access article distributed under the terms of the Creative Commons Attribution Non-Commercial License (http://creativecommons.org/licenses/by-nc/4.0) which permits unrestricted non-commercial use, distribution, and reproduction in any medium, provided the original work is properly cited. which they drop out of school. Their individual reasons and situations are different and complex, but typically involve the incidence of trauma associated with external environments. ${ }^{4)}$ In particular, dropping out of school often occurs as a result of either conflict with parents at home and abuse or bullying at school. ${ }^{4}$ A study of homeless youths also revealed a high rate of childhood trauma among runaway youths, such as physical, mental, sexual, and emotional abuses. ${ }^{5}$ After dropping out of school, OSYs are exposed to psychological distress and mental stress due to economic problems; running away from home and subsequent food, clothing, and shelter problems; and a miserable living environment. ${ }^{3)}$ As reported in previous studies, OSYs experience continuous and repetitive complex and multiple traumas beginning in childhood. $^{3,6)}$

Complex and multiple traumas are reported to be the sources of various psychological problems, such as deficient emotional self-regulation, poor attention and awareness, somatic symptoms, negative self-perception, and altered relationships 
with others. ${ }^{7)}$ According to previous studies, ${ }^{8,9)} 50-70 \%$ of homeless and runaway youths suffer from a range of psychological problems, including depression, substance abuse, problem behavior, and post-traumatic stress disorder (PTSD); this rate is significantly higher than that of youths in normal situations.

Many studies have reported that adolescence is a developmental stage marked by lowered quality of life (QOL) compared with other developmental stages, and that adolescents are more sensitive to routine and traumatic events. ${ }^{10)} \mathrm{QOL}$ is an important concept in health assessment; health-related QOL represents a multidimensional approach to defining QOL and considers all domains of life, including physical, psychological, social, and mental aspects, ${ }^{11)}$ with emphasis on mental and social stability beyond mere physical well-being. ${ }^{12)}$ Psychological well-being is an important aspect of $\mathrm{QOL}$, given the very nature of $\mathrm{QOL}$ as a subjective perception of the degree of satisfaction with life; notably, a previous report defined QOL as psychological well-being. ${ }^{10)}$

Despite the obvious correlations as suggested in these studies, there remains a lack of research regarding trauma exposure, psychological problems, and QOL among OSYs. This study attempted to bridge this research gap by examining correlations among these variables by testing two hypotheses: First, lifetime incidence of trauma will be correlated with both psychological problems and QOL. Second, psychological problems will mediate the relationship between lifetime incidence of trauma and QOL. This study aimed to identify the relationships among lifetime incidence of trauma, psychological problems, and QOL, in order to establish basic data regarding therapeutic strategies for improving the QOL of OSYs in clinical settings.

\section{METHODS}

\section{Participants}

For data collection, we retrospectively reviewed the medical records of 50 OSYs who were referred to a national hospital for health check-ups from July 2015 to November 2015. The OSYs subjected to health check-ups were recruited in OSY support organizations in Seoul and Gyeonggi-do areas (OSY protection centers and youth havens). We defined youth as children and young adults ages 9-24 years, pursuant to the Framework Act on Juveniles. An experienced pediatric mental health specialist assessed the mental health of each of the participants by using self-report questionnaires. This study was approved by the Institutional Review Board of the National Medicine Center (IRB No. 1601-062-008).

\section{Measurement instruments}

\section{Basic questionnaire survey}

We examined basic demographic characteristics of the participating OSYs: gender, age, school dropout age, school life satisfaction, and household economic status (ES). School life satisfaction was assessed on a five-point scale [from 1 (very dissatisfied) to 5 (very satisfied)]. Household ES was assessed based on two categories of National Health Insurance and Medical Aid, according to Korean National Health Insurance, whereby three different points, namely 1 (high ES), 2 (middle ES), and 3 (low ES), were assigned to the former, and 4 (lowest ES) was assigned to the latter.

\section{Lifetime Incidence of Traumatic Events for children}

Lifetime Incidence of Traumatic Events for children (LITE-C) is a self-report questionnaire developed by Greenwald and Rubin ${ }^{13)}$ as a checklist for screening and assessing the exposure to trauma in children and adolescents. Specifically, it assesses the type of trauma and loss events experienced by children and adolescents, age at the time of exposure, degree of impact at the time of occurrence, and the present aftermath effect. ${ }^{13)}$ It covers a broad range of potentially upsetting situations that can cause trauma to children and adolescents, such as a car accident, fire, death of a family member, exposure to threats, sexual assault, or witnessing violence. The LITE-C scale is based on a scoring system, but constitutes an assessment tool to record all details regarding the type and severity of traumatic events experienced by children and adolescents, many of which escape clinical detection. ${ }^{13)}$ In defining the lifetime incidence of trauma, we regarded the exposure to one or more cases of one type of trauma as one lifetime incidence of trauma. The final score reflecting the absence or presence of each of the 16 types of trauma and loss events listed in the LITE-C was used to define multiple lifetime incidences of trauma-a higher score indicated a higher variety of trauma exposure. The test-retest reliability of LITE-C was determined to be $0.80(\mathrm{p}<0.001){ }^{13,14)}$

\section{Korean Youth Self Report}

Youth Self Report (YSR), developed by Achenbach and Rescorla $^{15)}$ is a self-report questionnaire for measuring adaptive functioning and emotional and behavioral problems in adolescents ages $11-18$ years. Oh et al. ${ }^{16)}$ constructed an adapted and standardized Korean version of YSR, which was used in this study. The YSR consists of 119 items assessed on a three-point Likert scale. For the purpose of this study, we used the Internalizing problems (anxious/depressed, withdrawn, and somatic complaints syndromes) subscales of the Problem Syndrome scales. Cronbach's alpha (internal consistency) for 
the Internalizing scales was determined to be $0.93 .^{15,16)}$

\section{Korean KIDSCREEN-27 quality of life measure} for children and adolescents

KIDSCREEN is a self-report questionnaire developed by the European Commission as a psychometric instrument for assessing health and well-being in children and adolescents ages $8-18$ years, by using subjective perception or observation for seven days. ${ }^{17)}$ KIDSCREEN has three respective versions consisting of 10, 27, and 52 items; there are Korean $(\mathrm{K})$ versions for KIDSCREEN-27 and KIDSCREEN-52. ${ }^{18)}$ We used K-KIDSCREEN-27, consisting of five domains: physical well-being (five items), psychological well-being (seven items), autonomy and parent relations (seven items), social support and peers (four items), and school environment (four items). Each item is rated on a five-point Likert scale. The domain "School Environment" was excluded from analysis because it does not apply to OSYs.

\section{Statistical analysis}

The data collected were analyzed with IBM SPSS statistics version 23.0 (IBM Corp., Armonk, NY, USA). Specifically, the following analyses were performed: descriptive statistics for demographics; one-sample t-tests to test gender dif- ferences; pearson correlation analysis to determine correlations among lifetime incidence of trauma, internalizing symptoms, and QOL; and multiple regression analysis with SPSS process. ${ }^{19)}$ Furthermore, we performed a bootstrapping test $^{20)}$ to validate the statistical significance of the indirect effect. We performed random sampling with replacement, using 5000 iterations, and interpreted the indirect effect as statistically significant if zero was not included in the $95 \%$ confidence interval (CI).

\section{RESULTS}

\section{Demographic characteristics}

Our surveyees were 50 OSYs ages 13-23 years [mean $=18.80$ years, standard deviation $(\mathrm{SD})=1.62$ years] with no significant gender difference (male: $\mathrm{n}=24,48 \%$; female: $\mathrm{n}=26,52 \%$ ). The mean school dropout age was 16.52 years $(\mathrm{SD}=1.58)$, which corresponds to the 10th or 11th grade. The mean school life satisfaction was 2.57, which was between 2 (neutral) and 3 (dissatisfied) points; the mean household ES was 2.72, which was between 2 (middle) and 3 (low) points (Table 1). No statistically significant differences were observed except for age [ $\mathrm{t}(48)=-2.141, \mathrm{p}<0.05]$. The surveyees' mean lifetime incidence of trauma was $3.27(\mathrm{SD}=2.41)$. Of the 50 surveyees,

Table 1. Demographic characteristics $(n=50)$

\begin{tabular}{|c|c|c|c|}
\hline Variable & $\begin{array}{c}\text { Male }(n=24) \\
\text { mean } \pm S D\end{array}$ & $\begin{array}{c}\text { Female }(n=26) \\
\text { mean } \pm S D\end{array}$ & $\begin{array}{c}\text { Total }(n=50) \\
\text { mean } \pm S D\end{array}$ \\
\hline Age (years)* & $19.29 \pm 1.52$ & $18.35 \pm 1.60$ & $18.80 \pm 1.62$ \\
\hline School stop age (years) & $16.57 \pm 1.62$ & $16.48 \pm 1.59$ & $16.52 \pm 1.58$ \\
\hline School life satisfaction & $2.52 \pm 0.87$ & $2.61 \pm 0.99$ & $2.57 \pm 0.93$ \\
\hline Economic status & $2.70 \pm 0.88$ & $2.75 \pm 0.68$ & $2.72 \pm 0.77$ \\
\hline LITE-C & $2.96 \pm 2.42$ & $3.56 \pm 2.42$ & $3.27 \pm 2.41$ \\
\hline YSR_Internalizing ${ }^{\dagger}$ & $58.62 \pm 8.00$ & $59.79 \pm 6.85$ & $59.24 \pm 7.35$ \\
\hline YSR_Anxious/depressed & $57.13 \pm 9.53$ & $58.65 \pm 10.94$ & $57.94 \pm 10.22$ \\
\hline YSR_Withdrawn/depressed & $59.09 \pm 9.75$ & $60.00 \pm 7.68$ & $59.57 \pm 8.63$ \\
\hline YSR_Somatic & $59.65 \pm 10.40$ & $60.73 \pm 9.14$ & $60.22 \pm 9.66$ \\
\hline KIDSCREEN_Psychological well-being & $23.21 \pm 7.01$ & $22.23 \pm 4.76$ & $22.70 \pm 5.90$ \\
\hline
\end{tabular}

${ }^{*} p<0.05$, internalizing mean of Anxious/depressed, Withdrawn/depressed, Somatic. LITE-C: Lifetime Incidence of Traumatic Events for Children, SD: standard deviation, YSR: Youth Self Report

Table 2. Correlation coefficients of the study variables $(n=50)$

\begin{tabular}{|c|c|c|c|c|c|}
\hline Variable & 1 & 2 & 3 & 4 & 5 \\
\hline \multicolumn{6}{|l|}{ 1. LITE-C } \\
\hline 2. YSR_Internalizing ${ }^{\ddagger}$ & $0.466^{\dagger}$ & & & & \\
\hline 3. YSR_Anxious/depressed & $0.420^{\dagger}$ & $0.874^{\dagger}$ & & & \\
\hline 4. YSR_Withdrawn/depressed & 0.145 & $0.772^{\dagger}$ & $0.656^{\dagger}$ & & \\
\hline 5. YSR_Somatic & $0.470^{\dagger}$ & $0.669^{\dagger}$ & $0.351^{*}$ & 0.147 & \\
\hline 6. KIDSCREEN Psychological well-being & $-0.342 *$ & $-0.586^{\dagger}$ & $-0.620^{\dagger}$ & $-0.631^{\dagger}$ & -0.118 \\
\hline
\end{tabular}

${ }^{*} p<0.05,{ }^{\dagger} p<0.01$, ${ }^{\ddagger}$ internalizing mean of Anxious/depressed, Withdrawn/depressed, Somatic. LITE-C: Lifetime Incidence of Traumatic Events for Children, YSR: Youth Self Report 
21 (52\%) experienced the separation or divorce of their parents, and 15 (30\%) reported the experience of being hit, beaten, battered, or injured.

\section{Correlations analyses}

Table 2 presents the results of bivariate correlation analyses performed to test the research hypotheses. First, lifetime incidence of trauma showed a statistically significant positive correlation with the YSR internalizing symptoms ( $\mathrm{r}=0.466$, $\mathrm{p}<0.01)$. When the individual internalizing symptoms were analyzed separately, anxious/depressed and somatic were
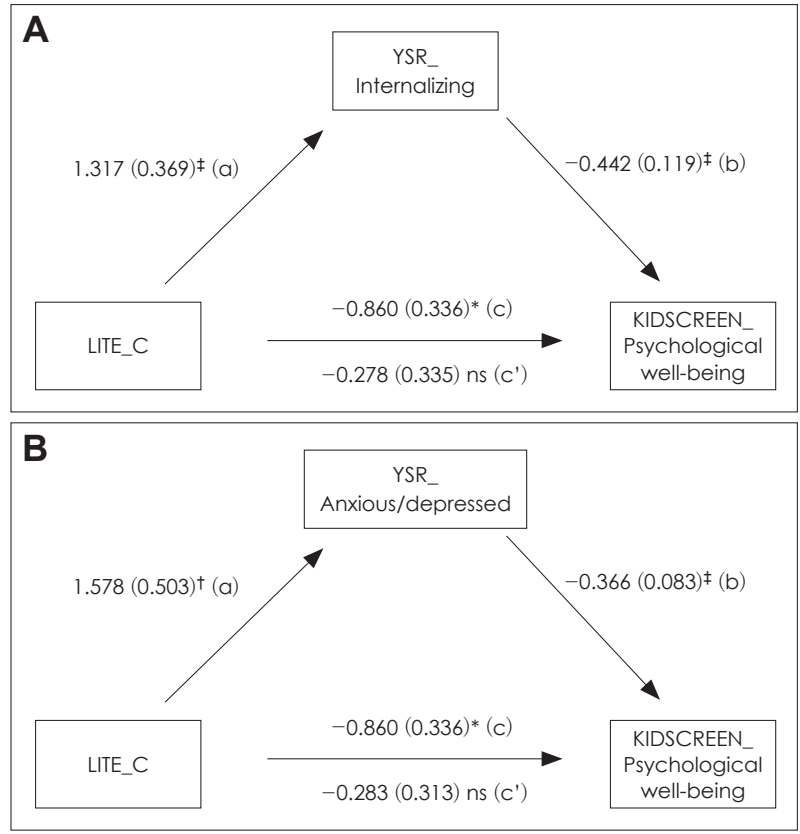

Fig. 1. Mediation diagram of lifetime incidence of traumatic events on quality of life related to psychological well-being through (A) Internalizing and (B) Anxious/depressed in YSR among out-of-school youths. ${ }^{*} p<0.05,{ }^{t} p<0.01$, ${ }^{\ddagger} p<0.001$. LITE-C: Lifetime Incidence of Traumatic Events for Children, ns: not significant, YSR: Youth Self Report. found to have statistically significant positive correlations $(r=$ $0.420, \mathrm{p}<0.01 ; \mathrm{r}=0.470, \mathrm{p}<0.01)$. Second, lifetime incidence of trauma showed a statistically significant negative correlation with QOL (KIDSCREEN Psychological Well-Being) $(\mathrm{r}=-0.342, \mathrm{p}<0.05)$. Third, the YSR internalizing symptoms showed a statistically significant negative correlation with the KIDSCREEN Psychological Well-Being $(\mathrm{r}=-0.586, \mathrm{p}<0.01)$ (Table 2).

\section{Mediation models}

We tested the indirect effect of the lifetime incidence of trauma (LITE-C) on QOL (KIDSCREEN Psychological WellBeing) through the mediation of psychological problems (YSR internalizing symptoms) (Fig. 1A). The test demonstrated that although the direct effect of the lifetime incidence of trauma on QOL was not statistically significant (c'), its indirect effect on QOL through the mediation of internalizing symptoms was statistically significant (c). More specifically, participants with higher LITE-C scores (i.e., more frequent exposure to various types of trauma) showed higher internalizing scores, which in turn further decreased their psychological well-being QOL (b).

To examine whether and how each of the three internalizing symptoms (anxious/depressed, withdrawn/depressed, and somatic) was influenced by the exposure to various traumatic events, and to measure their further influences on QOL, we constructed three separate mediation models. We found no statistically significant correlations in the models with the withdrawn/depressed and somatic symptoms as mediator variable (Table 3). Lifetime incidence of trauma exerted a statistically significant effect on QOL (c') only in the model with the anxious/depressed symptom as the mediator variable, with symptoms significantly increasing as the lifetime incidence of trauma increased (a, Fig. 1B). Furthermore, if the anxious/depressed symptom increased, with the lifetime in-

Table 3. The indirect effect of the YSR_Internalizing between the LITE-C and the KIDSCREEN_Psychological well-being ( $n=48$ )

\begin{tabular}{|c|c|c|c|c|c|c|c|c|c|c|c|c|}
\hline \multirow{3}{*}{ Paths } & \multicolumn{12}{|c|}{ Indirect variable } \\
\hline & \multicolumn{3}{|c|}{ YSR_Internalizing ${ }^{\S}$} & \multicolumn{3}{|c|}{$\begin{array}{l}\text { YSR_Anxious/ } \\
\text { depressed }\end{array}$} & \multicolumn{3}{|c|}{$\begin{array}{c}\text { YSR_Withdrawn/ } \\
\text { depressed }\end{array}$} & \multicolumn{3}{|c|}{ YSR_Somatic } \\
\hline & B & SE & $\dagger$ & B & SE & $t$ & B & SE & $t$ & B & SE & $t$ \\
\hline$x \rightarrow 1(a)$ & 1.317 & 0.369 & $3.569^{\ddagger}$ & 1.578 & 0.503 & $3.140^{\dagger}$ & 0.509 & 0.511 & 0.996 & 1.864 & 0.546 & $3.614^{\ddagger}$ \\
\hline$\mapsto \rightarrow Y(b)$ & -0.442 & 0.119 & $-3.727^{\ddagger}$ & -0.366 & 0.083 & $-4.392^{\ddagger}$ & -0.400 & 0.078 & $-5.151^{\ddagger}$ & 0.062 & 0.097 & 0.639 \\
\hline Total effect (c) & -0.860 & 0.336 & $-2.561^{*}$ & -0.860 & 0.336 & $-2.561^{*}$ & -0.860 & 0.336 & $-2.561^{*}$ & -0.860 & 0.336 & $-2.561^{*}$ \\
\hline Direct effect (c') & -0.278 & 0.335 & -0.829 & -0.283 & 0.313 & -0.903 & -0.656 & 0.272 & $-2.411^{*}$ & -0.975 & 0.383 & $-2.546^{*}$ \\
\hline $\begin{array}{l}\text { Indirect effects, } \\
95 \% \mathrm{Cl}(\mathrm{BC})\end{array}$ & \multicolumn{3}{|c|}{$[-1.173,-0.187]$} & \multicolumn{3}{|c|}{$[-1.186,-0.191]$} & \multicolumn{3}{|c|}{$[-0.650,0.055]$} & \multicolumn{3}{|c|}{$[-0.276,0.726]$} \\
\hline
\end{tabular}


cidence of trauma controlled, QOL decreased with statistical significance (b).

We tested the validity of mediation of the model by using anxious/depressed as the mediator variable with bootstrapping. As a result, the indirect effect of the lifetime incidence of trauma on QOL through the mediation of anxious/depressed was found to be statistically significant, with the $95 \%$ CI not including zero (-1.186--0.191).

\section{DISCUSSION}

The present study analyzed the correlations among lifetime incidence of trauma, internalizing symptoms, and QOL in OSYs. The analysis results can be summarized as follows: 1) lifetime incidence of trauma was positively correlated with internalizing symptoms and negatively correlated with QOL, 2) even in OSYs with a high lifetime incidence of trauma (LITE-C), fewer or less severe psychological problems (YSR internalizing symptoms) contributed to an enhanced QOL (KIDSCREEN Psychological well-being), and 3) of the internalizing symptoms, anxious/depressed was particularly affected by lifetime incidence of trauma and exerted significant effects on QOL.

The mean complex and multiple lifetime incidence of trauma experienced by the participants (50 OSYs) was 3.27 (SD= 2.41). Family-related traumas, such as family violence and parental negligence, and school-related traumas, such as bullying and other forms of school violence, are reported to be causes of dropping out of school. ${ }^{4}$ After dropping out of school, OSYs tend to engage more actively in risk-taking behaviors, such as runaway/rebellious behavior, and nicotine and alcohol abuse; the accompanying economic burdens make them more vulnerable to exposure to further complex and multiple traumas such as labor exploitation, abuse or violence, and, primarily involving girls, sexual assault or prostitution. ${ }^{21)}$ In particular, exposure to complex and multiple traumas in childhood and adolescence leads to more comprehensive and diversified mental diseases than those experienced as adults, given their associations with attachment relationships with parents or primary caregivers. ${ }^{22)}$ It has also been reported that experiences of abuse during childhood and adolescence are carried into adulthood and adversely affect victims' parenting behaviors, which can then be detrimental to their children's mental health. ${ }^{23)}$ Such findings support the views that the sequelae of complex and multiple traumas experienced in childhood and adolescence have longlasting effects.

Previous studies of OSYs have reported that they are not prepared for normal developmental tasks in family and school life and are prone to psychological distress due to poor liv- ing conditions; these factors place OSYs at higher risks of depression, substance abuse, and problem behaviors. ${ }^{8,24)} \mathrm{A}$ Korean study of runaway youths also reported enhanced risks of depression, addiction, and attachment problems among runaway youths. ${ }^{25)}$ The rates of attempted suicide among runaway and homeless adolescents were reported to be threefold higher than that of general adolescents $(10-37 \%$ vs. 3$19 \%)^{26,27)}$ This suggests the need for active evaluation of therapeutic interventions for mental health in OSYs.

Adolescence is a stage of transition into adulthood, and the mental health and subjectively perceived QOL of adolescents are of particular importance because, not only do they have direct effects on all aspects of individual lives (e.g., career and social integration), they also influence others and society in terms of family and work life; thus, mental health problems in adolescence can impose a large and lasting burden on society. ${ }^{3)}$ The fact that children and adolescents with mental health problems report low QOL more often than those with physical health problems highlights the important of mental health. $\left.{ }^{28}\right)$ OSYs or runaway youths are likely to have low QOL because they are constantly exposed to various psychological traumas and are at higher risk of suffering from complex and multiple traumas without the protection of a supportive family or school environment. ${ }^{29)}$

In this study, OSYs' internalizing symptoms were identified to be the mediator positively correlated with lifetime incidence of trauma and negatively correlated with QOL related to psychological well-being, enabling the lifetime incidence of trauma to have an indirect effect on QOL. This implies that OSYs with a history of complex and multiple traumas accompanied by internalizing symptoms are likely to have lowered QOL. According to a study on the cumulative effects of childhood trauma, ${ }^{22)}$ childhood abuse, regardless of frequency, is linked to an increased risk of depression and lowered QOL if accompanied by PTSD; importantly, QOL is further lowered through repeated exposure to childhood abuse. The fact that trauma-induced psychological problems are especially detrimental to QOL was supported by a study ${ }^{30)}$ that reported that depression and anxiety disorder lowered QOL, and that this effect was aggravated if accompanied by PTSD.

This study has the following limitations. First, the survey sample lacks population representativeness due to selection bias, since the participating OSYs were recruited only in Seoul and Gyeonggi-do areas. In a follow-up study, the survey sample (OSYs) should be drawn from youth havens and protection centers across the nation. Second, particular care had to be taken when performing result analysis due to the small sample size and cross-sectional study design. In research involving adolescents, gender can act as a major confounding 
variable because adolescence is a period characterized by rapid physical and psychological changes. In this study, however, no significant gender difference was observed. Furthermore, although this was a cross-sectional study, it was difficult to clarify the causal relationships among lifetime incidence of trauma, internalizing symptoms, and QOL. These problems must be addressed by conducting a longitudinal study with a larger sample size. Third, the major disadvantage of self-report questionnaires, as used in this study, is a response bias that may lower data reliability. Notably, in the case of LITE-C, assessment is made on the basis of the number of trauma types, rather than the frequency of traumatic events of each type, resulting in underestimation of the actual number of trauma exposures. This can be addressed by a systematic, longitudinal study with nationwide sampling of OSYs.

Despite these limitations, this study is significant in that it analyzed the correlations among lifetime incidence of trauma, internalizing symptoms, and QOL in OSYs. The analysis revealed that the internalizing symptoms (psychological problems) of OSYs mediated an indirect effect of the lifetime incidence of trauma on QOL related to psychological well-being. From this, it can be inferred that QOL can be improved in cases of fewer or less severe internalizing symptoms, even in the presence of a high lifetime incidence of trauma. Therefore, clinicians and counselors must evaluate the absence/presence of internalizing symptoms in OSYs and administer adequate intervention programs to improve their QOL.

\section{CONCLUSION}

The present study verified the correlations among lifetime incidence of trauma, internalizing symptoms, and QOL in OSYs. Mean lifetime incidence of complex and multiple traumas was 3.72 (number of trauma types) and QOL was found to be higher when there were fewer or less severe internalizing symptoms, even in cases of high trauma exposure. The results of this study highlight the need for our society to increase efforts to improve the QOL of OSYs to prevent individual and societal losses by screening for internalizing symptoms and implementing measures for therapeutic interventions.

\section{Acknowledgments}

The present study was supported by a grant from the Korea Healthcare Technology R\&D Project, Ministry of Health and Welfare, Republic of Korea (HM15C1054).

\section{Conflicts of Interest}

The authors have no financial conflicts of interest.

\section{REFERENCES}

1) National Youth Policy Institute. A longitudinal survey and support plan for dropouts I. Sejong: National Youth Policy Institute; 2013 [cited 2018 May 24]. Available from URL: http://lib.nypi.re.kr/pdfs/ 2013/18.pdf.

2) Ministry of gender equality and family. Development direction ot prevention policy of suspension of study. Seoul: Ministry of gender equality and family; 2014 [cited 2018 May 24]. Available from URL: https://www.kyci.or.kr/fileup/lib_pdf/2014-08.pdf.

3) Ministry of education. Announcement of results of the survey on the interruption of schooling in 2012. Sejong: Ministry of education; 2012 [cited 2018 May 24]. Available from URL: https://www.moe. go.kr/boardCnts/view.do?boardID $=294 \&$ boardSeq $=50244 \& l e v=0$ \&searchType $=$ S\&statusYN $=$ W\&page $=220 \& s=$ moe $\& m=0503 \&$ op Type $=$.

4) Hammond C, Linton D, Smink J, Drew S. Dropout risk factors and exemplary programs. Clemson, SC: National Dropout Prevention Center, Communities In Schools; 2007 [cited 2018 May 24]. Availabble from URL: https://files.eric.ed.gov/fulltext/ED497057.pdf.

5) Keeshin BR, Campbell K. Screening homeless youth for histories of abuse: prevalence, enduring effects, and interest in treatment. Child Abuse Negl 2011;35:401-407.

6) Cook A, Spinazzola J, Ford J, Lanktree C, Blaustein M, Cloitre M, et al. Complex trauma in children and adolescents. Psychiatr Ann 2017;35:390-398.

7) Terr L. Unchained memories: true stories of traumatic memories lost and found. New York: Basic Books;1994. p.152-182.

8) Whitbeck LB, Johnson KD, Hoyt DR, Cauce AM. Mental disorder and comorbidity among runaway and homeless adolescents. J Adolesc Health 2004;35:132-140.

9) Martinez RJ. Understanding runaway teens. J Child Adolesc Psychiatr Nurs 2006;19:77-88.

10) Naess S. Quality of life as psychological well-being. Tidsskr Nor Laegeforen 2001;121:1940-1944.

11) Spilker B. Quality of life and pharmacoeconomics in clinical trials. Philadelphia: Lippincott Williams \& Wikins;1995. p.49-64.

12) Eiser C, Morse R. A review of measures of quality of life for children with chronic illness. Arch Dis Child 2001;84:205-211.

13) Greenwald R, Rubin A. Assessment of posttraumatic symptoms in children: development and preliminary validation of parent and child scales. Res Soc Work Pract 1999;9:61-75.

14) Han DH, Lee JJ, Moon DS, Cha MJ, Kim MA, Min S, et al. Korean version of inventory of complicated grief scale: psychometric properties in Korean adolescents. J Korean Med Sci 2016;31:114-119.

15) Achenbach T, Rescorla LA. Manual for the ASEBA school-age forms \& profiles: an integrated system of multi-informant assessment. Burlington: University of Vermont;2001. p1-9.

16) Oh K, Hong K, Lee H, Ha E. Korean-Youth Self Report (K-YSR). Seoul: Jungang Aptitude Research Center;1997.

17) Ravens-Sieberer U, Auquier P, Erhart M, Gosch A, Rajmil L, Bruil J, et al. The KIDSCREEN-27 quality of life measure for children and adolescents: psychometric results from a cross-cultural survey in 13 European countries. Qual Life Res 2007;16:1347-1356.

18) Hong SD, Yang JW, Jang WS, Byun H, Lee MS, Kim HS, et al. The KIDSCREEN-52 quality of life measure for children and adolescents (KIDSCREEN-52-HRQOL): reliability and validity of the Korean version. J Korean Med Sci 2007;22:446-452.

19) Preacher KJ, Hayes AF. Asymptotic and resampling strategies for assessing and comparing indirect effects in multiple mediator models. Behav Res Methods 2008;40:879-891.

20) Shrout PE, Bolger N. Mediation in experimental and nonexperimental studies: new procedures and recommendations. Psychol Methods 2002;7:422-445.

21) Whitbeck LB, Simons RL. A comparison of adaptive strategies and patterns of victimization among homeless adolescents and adults. 
Violence Vict 1993;8:135-152.

22) Agorastos A, Pittman JO, Angkaw AC, Nievergelt CM, Hansen CJ, Aversa LH, et al. The cumulative effect of different childhood trauma types on self-reported symptoms of adult male depression and PTSD, substance abuse and health-related quality of life in a large active-duty military cohort. J Psychiatr Res 2014;58:46-54.

23) Riser DK. Parent trauma history and parenting style: relation to child trauma and child psychopathology. Virginia: faculty of Virginia Polytechnic Institute and State University;2009.

24) Whitbeck LB, Hoyt DR, Ackley KA. Families of homeless and runaway adolescents: a comparison of parent/caretaker and adolescent perspectives on parenting, family violence, and adolescent conduct. Child Abuse Negl 1997;21:517-528.

25) Ko M, Hong MH, Kim YE, Ha J, Lee SM, Kim HS. Depression, attachment and addiction problems in runaway youths. J Korean Acad Child Adolesc Psychiatry 2016;27:181-187.
26) Greene JM, Ringwalt CL. Youth and familial substance use's association with suicide attempts among runaway and homeless youth. Subst Use Misuse 1996;31:1041-1058.

27) Feitel B, Margetson N, Chamas J, Lipman C. Psychosocial background and behavioral and emotional disorders of homeless and runaway youth. Hosp Community Psychiatry 1992;43:155-159.

28) Dada O, Odukoya O, Okuyemi K. Risk perception and correlates of alcohol use among out-of-school youth in motor parks in Lagos State, Nigeria. Malawi Med J 2016;28:19-25.

29) Sawyer MG, Whaites L, Rey JM, Hazell PL, Graetz BW, Baghurst P. Health-related quality of life of children and adolescents with mental disorders. J Am Acad Child Adolesc Psychiatry 2002;41:530-537.

30) Clark DB, Kirisci L. Posttraumatic stress disorder, depression, alcohol use disorders and quality of life in adolescents. Anxiety 1996; 2:226-233. 